\title{
Stroke unit care: recurrence, mortality and institutionalisation rates-a four year follow-up study
}

\author{
T. Walsh $\cdot$ T. Donnelly $\cdot$ S. Carew $\cdot$ C. O' Connor * \\ R. O' Riordan · D. Lyons
}

Published online: 22 April 2008

(C) Royal Academy of Medicine in Ireland 2008

\section{Erratum to: Ir J Med Sci}

\section{DOI 10.1007/s11845-007-0110-2}

The incorrect Abstract was submitted with this article. The correct abstract should read as follows:

Background The benefits of stroke unit care in terms of reducing mortality, morbidity and the need for institutional care in the short term are clear. Less evidence exists of its longer term benefits.

Aim The aim of this study was to measure the rates of mortality, institutionalisation and stroke recurrence over a 4-year period following stroke unit care.
Methods Discharge and 4-year follow-up data were examined on all patients admitted to the Stroke Rehabilitation Unit between September 2000 and August 2002. The results were compared with previously published data.

Results After 4 years $8 \%$ of patients had sustained a recurrent stroke, $40 \%$ were deceased and $40 \%$ were in institutional care.

Conclusions Compared to international data care at our unit appears to be associated with a lower rate of recurrent stroke and mortality but a higher institutionalisation rate after 4 years. The reasons for this are unclear.

The online version of the original article can be found under doi:10.1007/s11845-007-0110-2.

T. Walsh $\cdot$ T. Donnelly $\cdot$ S. Carew $\cdot$ D. Lyons

Department of Medicine for the Elderly,

Mid-Western Regional Hospital, Limerick, Ireland

e-mail: thomaswalsh_3@hotmail.com

C. O' Connor

Stroke Unit, St. Camillus' Hospital, Shelbourne Rd.,

Limerick, Ireland

R. O' Riordan

Day Hospital, St. Camillus' Hospital, Shelbourne Rd.,

Limerick, Ireland

D. Lyons ( $\square)$

Clinical Age Assessment Unit, Mid-Western Regional Hospital,

Dooradoyle, Limerick, Ireland

e-mail: declanlyons@elive.ie 